\title{
Long-term Response to First-line Pazopanib Therapy in mRCC Patients: A Multicenter Italian Experience
}

\author{
ANDREA SBRANA $^{1}$, ELISA BIASCO $^{2}$, FEDERICO PAOLIERI $^{1}$, ERICA PALESANDRO $^{3}$, CLAUDIA CASERTA $^{4}$, \\ ROBERTO IACOVELLI ${ }^{5}$, BEATRICE DETTI ${ }^{6}$, DANIELE SANTINI ${ }^{7}$, ALESSANDRA MOSCA $^{8}$, \\ FRANCO MORELLI ${ }^{9}$, GIUSEPPE FORNARINI ${ }^{10}$, UGO DE GIORGI $^{11}$, CRISTINA MASINI $^{12}$ and LUCA GALLI ${ }^{1}$ \\ ${ }^{1}$ U.O. Oncologia Medica 2 Universitaria, Polo Oncologico, Azienda Ospedaliero-Universitaria Pisana, Pisa, Italy; \\ ${ }^{2}$ DH Oncologico Portoferraio, Azienda Toscana Nord Ovest, Livorno, Italy; \\ ${ }^{3}$ Istituto di Candiolo - IRCCS, Turin, Italy; \\ ${ }^{4}$ S. C. Oncologia Medica, Azienda Ospedaliera S. Maria, Terni, Italy; \\ ${ }^{5}$ U.O.C. Oncologia Medica, Azienda Ospedaliera Universitaria Integrata Verona, Verona, Italy; \\ ${ }^{6}$ U.O. Radioterapia, Azienda Ospedaliero-Universitaria Careggi, Florence, Italy; \\ ${ }^{7}$ U.O.S. Day Hospital di Oncologia, Università Campus Biomedico, Rome, Italy; \\ ${ }^{8}$ S.C. Oncologia Medica, Azienda Ospedaliero-Universitaria Maggiore della Carità, Novara, Italy; \\ ${ }^{9}$ U.O.C. Oncologia, Casa Sollievo della Sofferenza, San Giovanni Rotondo, Italy; \\ ${ }^{10}$ U.O. Oncologia Medica 1, Policlinico San Martino, Genoa, Italy; \\ ${ }^{11}$ U.O. Oncologia Medica, IRST, Meldola, Italy; \\ ${ }^{12}$ U.O. Oncologia Medica, Azienda Ospedaliera di Reggio Emilia, Reggio Emilia, Italy
}

\begin{abstract}
Background/Aim: The specific characteristics of patients who are most likely to benefit from pazopanib therapy are still uncertain. We report on the results of an Italian multicenter, retrospective analysis investigating the factors associated with longer response to first-line pazopanib in patients with metastatic renal cell carcinoma. Patients and Methods: Adult patients were considered if they had received treatment with pazopanib ( $800 \mathrm{mg} /$ day) for $>12$ months in the first-line setting. Results: In total, 112 patients were evaluated. Median duration of pazopanib treatment was 22.6 months (IQR 17.8 months). Median PFS was 22.6 months $(95 \%$ CI= 20.2-25.0). Eighty-three patients (74.1\%) had a PFS $\geq 18$ months. Median OS was 32.9 months $(95 \%$ CI=30.2-35.6). At statistical analysis, only PS score $(1+v s .0)$ was significantly associated with PFS (HR=1.76; 95\%CI=1.02-3.05; $p=0.04)$. Conclusion: Pazopanib therapy may be suitable for all patients with $\mathrm{mRCC}$, and especially in those with PSO.
\end{abstract}

Over the last years, a number of targeted and innovative therapies have been approved for the treatment of metastatic

Correspondence to: Andrea Sbrana, U.O. Oncologia Medica 2 Universitaria, Polo Oncologico, Azienda Ospedaliero-Universitaria Pisana, Pisa, Italy. Tel: +39 050992466, e-mail: andreasbrana89@ gmail.com

Key Words: mRCC, pazopanib, response, first-line. renal cell carcinoma (mRCC) in the so-called 'antiangiogenic era' $(1,2)$. In the first-line setting, the recent ESMO guidelines recommend a treatment with bevacizumab plus IFN- $\alpha$, sunitinib or pazopanib in patients with good or intermediate risk and clear-cell histology (3). The selection of therapy should be based upon patients' characteristics and the specific efficacy and safety profiles of each treatment $(4,5)$.

In particular, pazopanib $\left(\right.$ Votrient ${ }^{\circledR}$; Novartis, Basel, Switzerland), is an orally administered multi-targeted tyrosine kinase inhibitor that inhibits VEGFR-1, -2 and -3, PDGFR $-\alpha$ and $-\beta$, and the stem cell factor receptor c-Kit (6). This molecule was registered based on a global randomized, placebo-controlled, phase III study (7), and more recently it was shown to be as effective as sunitinib, but in association with a higher overall response rate (ORR) in the pivotal phase III COMPARZ trial $(8,9)$. Interestingly, the results of the crossover PISCES trial showed a patient preference for pazopanib over sunitinib (10).

However, the specific characteristics of patients who are most likely to benefit from pazopanib therapy remain to be fully disclosed (11). In a recent post-hoc analysis of the COMPARZ trial, presented at the 2017 ASCO meeting, no baseline factor associated with long duration of response to pazopanib treatment was identified. Noteworthy, data from daily clinical practice could complement the results of pivotal trials and help identify the patient who may show prolonged response to pazopanib therapy (11). 
Sample $(n=144)$

Analysed $(n=112)$

- Excluded from analysis because they

received a previous treatment with interleukin

$(n=2)$

- Excluded from analysis because they did not meet the inclusion criteria, namely as $>12$ months drug exposure $(n=30)$

Figure 1. Selection of patients.

Here, we report the results of an Italian multicenter analysis aimed at investigating the factors associated with longer response to first-line pazopanib in $\mathrm{mRCC}$ patients.

\section{Patients and Methods}

Study setting and design. This was a multicenter, retrospective study conducted in 20 oncological centers located all over the Italian territory. The local Ethical Committees have approved the study design; all patients had signed an informed consent to the use of their personal data for research purposes before enrolment.

Patient selection. Clinical charts of patients were reviewed to identify eligible subjects. Patients were included in this analysis if they met the following criteria: (i) age $\geq 18$ years at first diagnosis of mRCC; and (ii) had received treatment with pazopanib for $>12$ months in the first-line setting. No other inclusion or exclusion criteria were applied.

Treatment. Pazopanib was administered at the standard dose of $800 \mathrm{mg} /$ day. Supportive care and standard management were provided according to the practice of each participating center.

Evaluations. Progression-free survival (PFS) and overall survival (OS) were the primary efficacy endpoints. PFS was defined as the time from the initiation of pazopanib treatment to progression or death, whichever occurred first. Patients were censored if no progression or death was observed at the time of analysis. OS was defined as the time from treatment initiation to death; patients alive at the time of analysis were censored. Safety considerations were also performed.

Statistical analysis. Descriptive and comparative statistics were performed to evaluate the following patients' characteristics: age at diagnosis, histotype and prior nephrectomy, TNM staging before starting pazopanib, metastatic sites, performance status (PS) and Fuhrman grade before starting pazopanib, baseline haemoglobin, serum level of lactic dehydrogenase (LDH) before the initiation of therapy, baseline calcemia, duration of treatment, and best response to pazopanib according to the RECIST criteria, version 1.1. Laboratory measurements were performed according to the standard practice of each center.

PFS and OS were calculated using the Kaplan-Meier method. The log-rank test was used for comparison of the survival curves. Long-term responders to pazopanib were defined as patients with $\mathrm{PFS} \geq 18$ months. The Cox proportional hazards model was used to
Table I. Patients' demographic and clinical characteristics.

\begin{tabular}{|c|c|c|}
\hline Characteristic & $\mathrm{N}$ & $\%$ \\
\hline \multicolumn{3}{|l|}{ Gender } \\
\hline Women & 34 & 30.4 \\
\hline Men & 78 & 69.6 \\
\hline Age at diagnosis, mean (SD), years & $63.2(10.0)$ & \\
\hline Age at diagnosis (range), years & $37-85$ & \\
\hline \multicolumn{3}{|l|}{ Istotype } \\
\hline Clear cell RCC & 110 & 98.2 \\
\hline Non-clear cell RCC & 2 & 1.8 \\
\hline \multicolumn{3}{|l|}{ Prior nephrectomy } \\
\hline No & 5 & 4.5 \\
\hline Yes & 107 & 95.5 \\
\hline \multicolumn{3}{|l|}{ TNM staging } \\
\hline T1-2 N0 & 36 & 33.3 \\
\hline T3-4 N0 & 46 & 42.6 \\
\hline $\mathrm{T}$ any $\mathrm{N} 1$ & 7 & 6.5 \\
\hline $\mathrm{T}$ any $\mathrm{N}$ any $\mathrm{M} 1$ & 19 & 17.6 \\
\hline \multicolumn{3}{|l|}{ Mestastatic sites } \\
\hline Lung & 74 & - \\
\hline Liver & 9 & - \\
\hline Bones & 23 & - \\
\hline Pancreas & 12 & - \\
\hline Brain & 2 & - \\
\hline Lymph nodes & 54 & _- \\
\hline Other & 41 & - \\
\hline \multicolumn{3}{|l|}{ Performance status } \\
\hline 0 & 79 & 70.5 \\
\hline 1 & 30 & 26.8 \\
\hline 2 & 2 & 1.8 \\
\hline 4 & 1 & 0.9 \\
\hline \multicolumn{3}{|l|}{ Fuhrman grade } \\
\hline 1 & 1 & 1.0 \\
\hline 2 & 43 & 42.2 \\
\hline 3 & 41 & 40.2 \\
\hline 4 & 17 & 16.7 \\
\hline \multicolumn{3}{|l|}{ Baseline LDH } \\
\hline$<240 \mathrm{u} / 1$ & 42 & 37.5 \\
\hline $240+u / 1$ & 42 & 37.5 \\
\hline NA & 28 & 25 \\
\hline \multicolumn{3}{|l|}{ Baseline calcemia } \\
\hline$<10 \mathrm{mg} / \mathrm{dl}$ & 75 & 67.0 \\
\hline $10+\mathrm{mg} / \mathrm{dl}$ & 11 & 9.8 \\
\hline NA & 28 & 23.2 \\
\hline \multicolumn{3}{|l|}{ Anaemia $^{+}$} \\
\hline Women & 7 & 15.6 \\
\hline Men & 31 & 31.3 \\
\hline NA & 13 & \\
\hline \multicolumn{3}{|l|}{ Heng class risk } \\
\hline Favourable & 40 & 35.7 \\
\hline Intermediate & 46 & 41.1 \\
\hline Poor & 3 & 2.7 \\
\hline Missing/not evaluable & 23 & 20.5 \\
\hline
\end{tabular}

NA: Not available. ${ }^{+}$The cut-off of haemoglobin level for determining anaemia was $12.0 \mathrm{~g} / \mathrm{dl}$ for women and $13.0 \mathrm{~g} / \mathrm{l}$ for men.

analyse the association between clinical features at baseline and PFS, calculating the hazard ratio (HR) and 95\%CIs. The selection of variables was carried out using the significance obtained from 


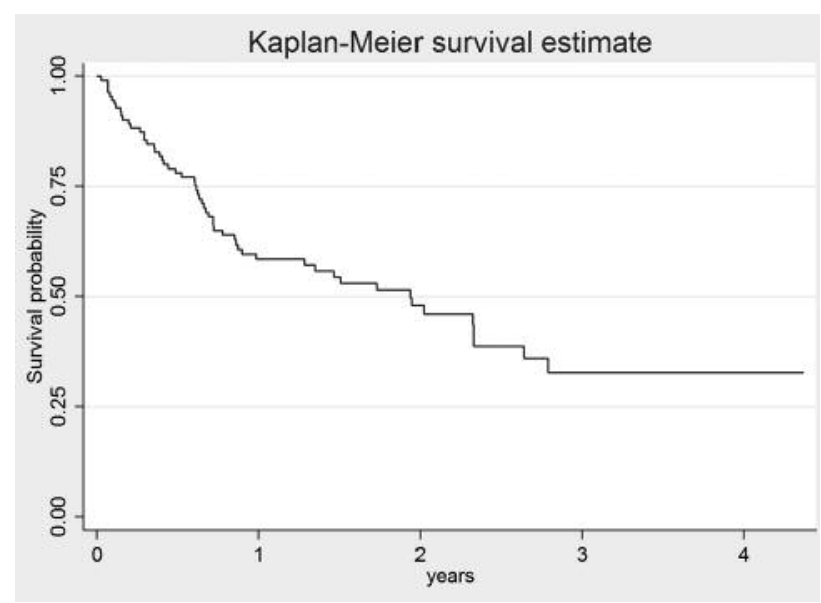

Figure 2. Kaplan-Meier analysis of progression-free survival.

the univariate Cox model, considering the significance level of $p \leq 0.2$, and relevance in the literature.

Adverse events were graded according to the Common Terminology Criteria for Adverse Events (CTCAE), version 4.0.

The EPI Info software (version 5.3 and 7) was used for descriptive analysis, and Stata (ver.11) for survival analysis.

\section{Results}

Baseline characteristics. In total, 112 patients met the inclusion criteria and were therefore evaluated (Figure 1). Table I shows patients' demographic and clinical characteristics. In total, 78 patients $(70 \%)$ were males; mean age at diagnosis was $63 \pm 10$ years (range $=37-85$ years). Only two patients $(2 \%)$ had a diagnosis of non-clear cell RCC. The wide majority of patients $(95.5 \%)$ had prior nephrectomy. The lungs were the most frequent metastatic site. Overall, 79 patients $(70.5 \%)$ had a PS of 0 ; Heng class of risk was favorable in 40 patients $(35.7 \%)$ and intermediate in $46(41.1 \%)$.

Median calcemia and LDH levels before starting pazopanib were $9.25 \mathrm{mg} / \mathrm{dl}$ (range=4.8-12.6 mg/dl) and $251.5 \mathrm{u} / \mathrm{l}$ (range $=126-500 \mathrm{u} / \mathrm{l}$ ), respectively. Forty-two (37.5\%) patients had baseline LDH levels higher than $240 \mathrm{u} / 1$. Patients with calcemia levels higher than $10 \mathrm{mg} / \mathrm{l}$ were 11 (9.8\%). For both variables, the percentage of missing data was about $20 \%$.

Four patients had neutropenia $\left(<1,700\right.$ cells $/ \mathrm{mm}^{3}$; information was missing for 17 patients). A total of ten patients (information was missing for 14 patients) had thrombocytopenia $\left(<150,000\right.$ cells $\left./ \mathrm{mm}^{3}\right)$.

Pazopanib therapy. Median duration of pazopanib treatment was 22.6 months (IQT: 17.8 months). Best response to pazopanib treatment was complete response in nine patients

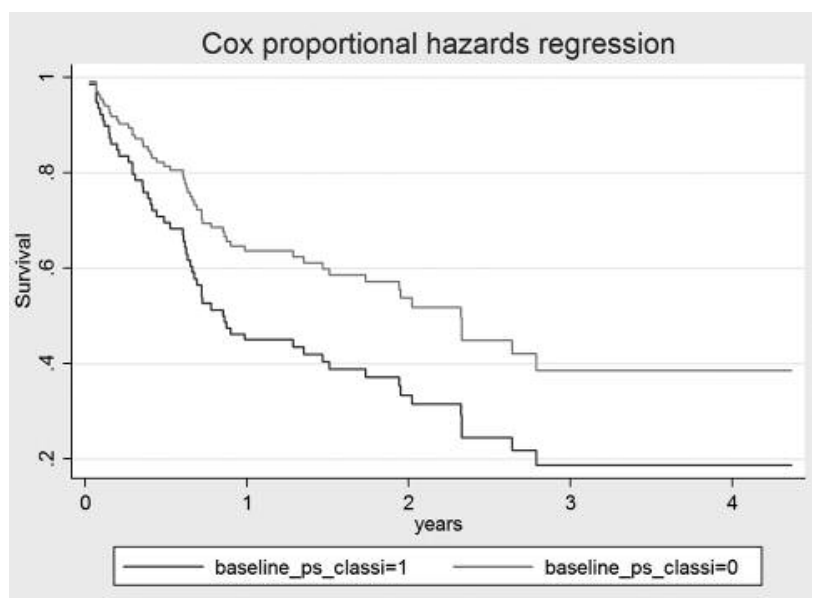

Figure 3. Kaplan-Meier analysis of progression-free survival according to progression-free survival.

Table II. Univariate analysis of progression-free survival.

\begin{tabular}{|c|c|c|c|c|}
\hline Parameter & $\begin{array}{l}\text { Hazard ratio } \\
\text { point estimate }\end{array}$ & $95 \% \mathrm{CI}$ & Coefficient & $p$-Value \\
\hline \multicolumn{5}{|c|}{ Continuous variables } \\
\hline Fuhrman grade & 1.42 & $0.98-2.08$ & 0.35 & 0.06 \\
\hline \multicolumn{5}{|c|}{ Categorical variables } \\
\hline \multicolumn{5}{|c|}{ PS*: } \\
\hline $1+$ & 1.76 & $1.02-3.05$ & 0.57 & 0.04 \\
\hline 0 & 1 & & & \\
\hline \multicolumn{5}{|l|}{ Gender: } \\
\hline Men & 0.82 & $0.46-1.45$ & -0.20 & 0.49 \\
\hline Woman & 1 & & & \\
\hline Baseline calcemia: & & & 0.41 & 0.43 \\
\hline$<10 \mathrm{mg} / \mathrm{dl}$ & 1.51 & $0.54-4.21$ & & \\
\hline $10+\mathrm{mg} / \mathrm{dl}$ & 1 & & & \\
\hline Baseline LDH: & & & 0.24 & 0.43 \\
\hline$<240 \mathrm{u} / 1$ & 1.27 & $0.70-2.28$ & & \\
\hline $240+u / 1$ & 1 & & & \\
\hline
\end{tabular}

$* p<0.05$

(8\%), partial response in 63 patients $(56.3 \%)$, and stable disease in 38 subjects (33.9\%); for two patients $(1.8 \%)$ information on best response to treatment was missing. Median follow-up time was 36.3 months. At the last followup visit, $56(50 \%)$ patients were still receiving pazopanib. In the remaining 56 patients, treatment was discontinued due to disease progression $(n=42)$, drug-related adverse events $(n=7)$, patient's choice $(n=5)$, while two patients had died.

Efficacy analysis. Median PFS was 22.6 months $(95 \% \mathrm{CI}=20.2-25.0)$ (Figure 2). Eighty-three patients $(74.1 \%)$ had a PFS $\geq 18$ months and were, therefore, defined as long- 
Table III. Multivariate analysis of progression-free survival.

\begin{tabular}{|c|c|c|c|c|c|c|}
\hline Parameter & $\begin{array}{l}\text { Hazard ratio point estimate } \\
\text { point estimate }\end{array}$ & $95 \% \mathrm{CI}$ & Coefficient & Standard error & Z-statistic & $p$-Value \\
\hline Baseline performance status $(0 / 1+)$ & 1.7612 & $1.0168-3.0505$ & 0.566 & 0.2803 & 2.0196 & 0.0434 \\
\hline
\end{tabular}

${ }^{\circ}$ Time 0 in the Cox model: 12 months.

term responders. Ninety-three patients $(83.0 \%)$ were still alive at the last follow-up; the median OS was 32.9 months (95\% CI=30.2-35.6).

As shown in Table II, PS $(1+v s$. 0$)$ was significantly associated with the PFS HR: 1.76, 95\% CI=1.02-3.05; $p=0.04)$. Other variables such as gender, LDH levels and calcemia levels did not reach a significance level of $p \leq 0.2$ and for this reason were not included in the Cox regression model. In the multivariate analysis (Table III and Figure 3), baseline PS was an independent predictor of PFS. No differences in PFS were reported between patients with favorable risk according to the Heng criteria (28.1 months; $95 \% \mathrm{CI}=26.3-30.9)$ and those with intermediate risk (26.8 months; 95\%CI: 24.7-29.0).

Characteristics of long-term responders. The patient characteristics were compared among patients with long-term response to pazopanib and those without (Table IV). Overall, there were more patients with PS 0 in the group with PFS $\geq 18$ months $(56 \%)$ than in the group with PFS $<18$ months $(44.0 \% ; p<0.05)$. Other patient characteristics such as baseline LDH and calcemia levels did not differ significantly between the two groups.

Safety analysis. Overall, the most common adverse events were hypertension and diarrhea (Table V). Twenty-three out of 223 adverse events were grade $\geq 3$. The most common grade $\geq 3$ adverse events were hypertension $(n=8)$ and diarrhea $(n=8)$. No deaths directly related to treatment were observed.

\section{Discussion}

The identification of the patient's and disease characteristics associated with prolonged response to first-line pazopanib therapy for mRCC may help guide treatment selection.

Although with all the limitations of any retrospective analysis (e.g., poor reporting and high number of missing data), this 'field-practice' study suggests that long response to pazopanib treatment may be achieved regardless of a number of baseline factors, which include gender, LDH levels and calcemia levels. On the other hand, baseline PS
Table IV. Patients characteristics according to PFS categories.

\begin{tabular}{|c|c|c|c|}
\hline $\begin{array}{l}\text { Response } \\
\text { categories }\end{array}$ & $\begin{array}{c}\text { PFS }<18 \\
\text { months, } \\
\text { n }(\%)\end{array}$ & $\begin{array}{c}\mathrm{PFS} \geq 18 \\
\text { months } \\
\mathrm{n}(\%)\end{array}$ & $\begin{array}{c}\text { Total } \\
(\mathrm{n}=112), \\
\mathrm{n}(\%)\end{array}$ \\
\hline \multicolumn{4}{|c|}{ Age at diagnosis (years) } \\
\hline Median & 66 & 66 & 65 \\
\hline Q1-Q3 & $58-70.5$ & $57-70$ & $57-70$ \\
\hline \multicolumn{4}{|l|}{ Gender } \\
\hline Women & $9(26.5)$ & $25(73.5)$ & $34(30.4)$ \\
\hline Men & $20(25.6)$ & $58(74.4)$ & $94(69.6)$ \\
\hline \multicolumn{4}{|c|}{ Performance status } \\
\hline 0 & $14(17.7)$ & $65(82.3)$ & $79(70.5)$ \\
\hline $1 / 2+$ & $15(45.5)$ & $18(54.5)$ & $33(29.5)$ \\
\hline \multicolumn{4}{|c|}{ Baseline LDH } \\
\hline$<240 \mathrm{u} / 1$ & $13(31.0)$ & $29(69.0)$ & $42(50)$ \\
\hline $240+\mathrm{u} / 1$ & $11(26.2)$ & $31(73.8)$ & $42(50)$ \\
\hline \multicolumn{4}{|c|}{ Baseline calcemia } \\
\hline$<10 \mathrm{mg} / \mathrm{dl}$ & $21(28.0)$ & $54(72.0)$ & $75(87.2)$ \\
\hline $10+\mathrm{mg} / \mathrm{dl}$ & $3(27.3)$ & $8(72.7)$ & $11(12.8)$ \\
\hline
\end{tabular}

Table V. Pazopanib treatment-related adverse events.

\begin{tabular}{lccc}
\hline Events* & All grades (n) & Grade 1/2 (n) & Grade 3/4 (n) \\
\hline AST/ALT alterations & 21 & 17 & 4 \\
Hypertension & 45 & 37 & 8 \\
Diarrhea & 62 & 56 & 6 \\
Cutaneous toxicity & 16 & 16 & 0 \\
Anemia & 10 & 10 & 0 \\
Hypothyroidism & 3 & 3 & 0 \\
Piastrinopenia & 9 & 8 & 1 \\
Neutropenia & 4 & 3 & 1 \\
Other & 53 & 50 & 3 \\
\hline
\end{tabular}

of 0 - indicative of good patient's overall status - was associated with prolonged OS. No special safety concerns were reported.

Our data are, overall, in line with those reported in the recent post-hoc analysis of the COMPARZ trial, which did not disclose any specific factor associated with longer 
response to pazopanib therapy (12). In more details, patients included in the intention-to-treat population of the pivotal COMPARZ trial were analyzed for differences in long-term response ( $\geq 10$ months) according to rate of response, PFS, and time to response. The overall percentage of long-term responders was $14 \%$ with pazopanib and $13 \%$ with sunitinib; corresponding figures for PFS were $31.4 \%$ and $33.6 \%$, respectively. This similar result between the two molecules was consistent regardless of the cut-off applied to define long-term duration of response and any other baseline characteristic. However, a shorter time to achieve complete or partial response was observed with pazopanib compared with sunitinib (11.9 weeks; 95\%CI=11.3-12.1 vs. 17.4 weeks; 95\% CI=12.7-18.0).

In another analysis, conducted in a 'field-practice' scenario and still unpublished, PS of 0 and history of nephrectomy were predictors of long-term response (13). A total of 153 patients treated with pazopanib were included; of them, 33 patients (22\%) were identified as long-term responders (median PFS: $\geq 18$ months). Median PFS was 27.2 months $(95 \% \mathrm{CI}=23.0-35.2)$ in long-term responders and 6.9 months $(95 \% \mathrm{CI}=5.0-8.5)$ in the remaining subjects. Noteworthy, and in line with our findings, long-term responders were more likely to have good PS at baseline $($ ECOG score $=0)(42.4 \%$ vs. $18.3 \% ; p=0.004)$. Moreover they were more likely to present a history of nephrectomy ( $81.8 \%$ vs. $57.5 \% ; p=0.010)$ than non-long-term responders. At multivariate analysis, both $\mathrm{ECOG}=0$ at baseline ( $v s$. $\mathrm{ECOG}=1(\mathrm{OR}=0.38 ; 95 \% \mathrm{CI}=0.16-0.89)$ and $v s . \mathrm{ECOG} \geq 2$ $(\mathrm{OR}=0.07,95 \% \mathrm{CI}=0.01-0.54))$ and history of nephrectomy $(\mathrm{OR}=3.33 ; 95 \% \mathrm{CI}=1.28-8.65)$ were confirmed as predictors of long-term response.

Similar investigations have also been performed for sunitinib (14). Differing from current findings on pazopanib, in a retrospective analysis of data from eight clinical trials and the expanded access program $(n=5,714)$, several factors, namely Caucasian ethnicity, ECOG=0, time from diagnosis to treatment $\geq 1$ year, clear cell histology, no liver metastasis, lactate dehydrogenase $\leq 1.5 \times \mathrm{ULN}$, corrected calcium $\leq 10 \mathrm{mg} / \mathrm{dl}$, hemoglobin above ULN, platelets $\leq \mathrm{ULN}$, body mass index $\geq 25 \mathrm{~kg} / \mathrm{m}^{2}$, and low neutrophil-to-lymphocyte ratio were associated with response lasting $\geq 18$ months.

Overall, we believe that the above-described results may help guide treatment selection.

\section{Conclusion}

Evidence collected to date in different settings seem to support that first-line pazopanib therapy may be suitable for all patients with $\mathrm{mRCC}$, and especially those with PS 0 . This finding definitely requires confirmation in a prospective study, conducted both in a 'field-practice' scenario and in a more selected trial setting.

\section{Conflicts of Interest}

The Authors have no conflicts of interest directly relevant to this study.

\section{Acknowledgements}

Editorial and scientific assistance for the preparation of this manuscript was provided by Luca Giacomelli, PhD, Lilia Biscaglia, $\mathrm{PhD}$, and Aashni Shah (Polistudium, Milan, Italy), on behalf of Content Ed Net; this assistance was supported by Novartis.

\section{References}

1 Choueiri TK and Motzer RJ: Systemic therapy for metastatic renal-cell carcinoma. N Engl J Med 376: 354-366, 2017.

2 Gill DM and Agarwa N: Cancer immunotherapy: A paradigm shift in the treatment of advanced urologic cancers. Urol Oncol pii: S1078-1439(17)30501-X, 2017. [Epub ahead of print]

3 Escudier B, Porta C, Schmidinger M, Rioux-Leclercq N, Bex A, Khoo V, Gruenvald V, Horwich A and ESMO Guidelines Committee: Renal cell carcinoma: ESMO Clinical Practice Guidelines for diagnosis, treatment and follow-up. Ann Oncol 27: v58-v68, 2016.

4 Kumar R and Kapoor A: Current management of metastatic renal cell carcinoma: evolving new therapies. Curr Opin Support Palliat Care 11(3): 231-237, 2017.

5 Ahmed SH, Elbaghdady N and Alorabi M: Application of the American Society of Clinical Oncology frameworks to compare tyrosine kinase inhibitors used in first line treatment of metastatic renal cell carcinoma: had we solved the mystery? Expert Rev Anticancer Ther 17(11): 1061-1070, 2017.

6 Frampton JE: Pazopanib: a review in advanced renal cell carcinoma. Target Oncol 12(4): 543-554, 2017.

7 Sternberg CN, Davis ID, Mardiak J, Szczylik C, Lee E, Wagstaff J, Barrios CH, Salman P, Gladkov OA, Kavina A, Zarbá JJ, Chen M, McCann L, Pandite L, Roychowdhury DF and Hawkins RE: Pazopanib in locally advanced or metastatic renal cell carcinoma: results of a randomized phase III trial. J Clin Oncol 28(6): 1061-1068, 2010.

8 Motzer RJ, Hutson TE, Cella D, Reeves J, Hawkins R, Guo J, Nathan P, Staehler M, de Souza P, Merchan JR, Boleti E, Fife $\mathrm{K}$, Jin J, Jones R, Uemura H, De Giorgi U, Harmenberg U, Wang J, Sternberg CN, Deen K, McCann L, Hackshaw MD, Crescenzo R, Pandite LN and Choueiri TK: Pazopanib versus sunitinib in metastatic renal-cell carcinoma. $\mathrm{N}$ Engl J Med 369(8): 722-731, 2013.

9 Motzer RJ, Hutson TE, McCann L, Deen K and Choueiri TK: Overall survival in renal-cell carcinoma with pazopanib versus sunitinib. N Engl J Med 370(18): 1769-1770, 2014.

10 Escudier B, Porta C, Bono P, Powles T, Eisen T, Sternberg CN, Gschwend JE, De Giorgi U, Parikh O, Hawkins R, Sevin E, Négrier S, Khan S, Diaz J, Redhu S, Mehmud F and Cella D: Randomized, controlled, double-blind, cross-over trial assessing treatment preference for pazopanib versus sunitinib in patients with metastatic renal cell carcinoma: PISCES Study. J Clin Oncol 32(14): 1412-1418, 2014. 
11 Porta C, Ferrari A, Czarnecka AM and Szczylik CA: Pazopanib in patients with clear-cell renal cell carcinoma: seeking the right patient. Front Pharmacol 8: 329, 2017.

12 Tannir NM, Porta C, Gruenwald V, Choueiri TK, Ahmad Q, Alfonso MC, Dezzani J, Han J and Sternberg CN: Long-term response and time to response to pazopanib (PAZ) and sunitinib (SUN) in metastatic renal cell carcinoma (mRCC): COMPARZ subanalysis. J Clin Oncol 35(suppl): abstr 4572, 2017.

13 Park J, Jiao X, Wilson T, Ghate S, Ahmad Q and Perez JR: Predictors of long-term responders in patients treated with pazopanib for advanced renal cell carcinoma (aRCC). J Clin Oncol 35(6 suppl): 524-524, 2017.
14 Tannir NM, Figlin RA, Gore ME, Michaelson MD, Motzer RJ Porta C6, Rini BI, Hoang C, Lin X and Escudier B: Long-term response to sunitinib treatment in metastatic renal cell carcinoma: a pooled analysis of clinical trials. Clin Genitourin Cancer pii: S1558-7673(17)30171-4, 2017. doi: 10.1016/ j.clgc.2017.06.005. [Epub ahead of print]

Received May 22, 2018

Revised June 11, 2018

Accepted June 12, 2018 